\title{
ANÁLISE DE MOBILIDADE SUSTENTÁVEL (DOTS): $O$ CASO DO CAMPUS TRINDADE DA UNIVERSIDADE FEDERAL DE SANTA CATARINA
}

\section{SUSTAINABLE MOBILITY ANALYSIS (TODS): THE CASE OF THE TRINDADE CAMPUS OF THE FEDERAL UNIVERSITY OF SANTA CATARINA}

\section{Fábio Pedroso Dias (UFSC); Arnoldo Debatin Neto, Dr. (UFSC)}

\section{Palavras Chave}

Desenvolvimento orientado ao transporte sustentável; Mobilidade sustentável; Campus universitário; Universidade Federal de Santa Catarina.

\section{Key Words}

Sustainable transport oriented development; Sustainable mobility; University campus; Federal University of Santa Catarina.

\section{RESUMO}

A larga utilização dos automóveis orientou decisões importantes no meio urbano e na mobilidade das cidades, amplamente difundindo um modelo de ocupação territorial distante, disperso e desconectado. Em contrapartida, o Desenvolvimento Orientado ao Transporte Sustentável (DOTS) se apresenta como uma chave para comunidades mais eficientes, sustentáveis e equitativas, pois prioriza a compactação, a coordenação e a conexão. Deparamo-nos também com a realidade do campus universitário frente à mobilidade sustentável - como o caso da Universidade Federal de Santa Catarina (UFSC), para o qual o presente trabalho analisa os estudos de mobilidade para estabelecer um panorama do campus e vinculá-lo ao repertório teórico do DOTS para gerar diretrizes conceituais para os princípios de mobilidade urbana sustentável no campus. $O$ trabalho se direciona para sete categorias de análise e cada cenário oferece uma reflexão crítica para a análise do DOTS e permitem fomentar a discussão para o desenvolvimento urbano sustentável.

\section{ABSTRACT}

The wide use of cars has guided important decisions in the urban environment and in the mobility of cities, widely disseminating a model of distant, dispersed and disconnected territorial occupation. On the other hand, Sustainable Transport Oriented Development (DOTS) is a key to more efficient, sustainable and equitable communities, as it prioritizes compaction, coordination and connection. We also find the reality of the university campus facing sustainable mobility - such as the case of the Federal University of Santa Catarina (UFSC), for which the present study analyzes mobility studies to establish a panorama of the campus and link it to the theoretical repertoire of DOTS to generate conceptual guidelines for the principles of sustainable urban mobility on campus. The work is directed to seven categories of analysis and each scenario offers a critical reflection for the DOTS analysis and allows to foment the discussion for the sustainable urban development. 


\section{INTRODUÇÃO}

A abordagem dos transportes sustentáveis tem sido utilizada como base para as novas transformações no meio urbano, através de conceitos e aplicações para redescobrir maneiras em que o planejamento pode ser mais bem incorporado e diminuir a dependência do automóvel (ITDP, 2017). O Desenvolvimento Orientado ao Transporte Sustentável (DOTS) aponta para comunidades mais eficientes, sustentáveis e equitativas porque prioriza a compactação, a coordenação e a conexão. As cidades universitárias, nesse contexto, precisam de estratégias que não sejam agressivas ao meio ambiente, tornando-se modelo para a sociedade e campo de estudo e aplicação prática para a academia.

O presente trabalho tem como objetivo contextualizar e analisar os estudos de mobilidade já realizados na Universidade Federal de Santa Catarina (UFSC) e suas conexões com a cidade; a fim de estabelecer um panorama da UFSC e vincula-lo ao repertório teórico do Desenvolvimento Orientado ao Transporte Sustentável (DOTS) e ponderar para os princípios de mobilidade urbana sustentável no campus, evidenciando como o futuro do transporte pode se complementar com desenvolvimento urbano, de uma forma sustentável.

Esta pesquisa parte do pressuposto de que, atualmente, o campus da UFSC apresenta inúmeras consequências de décadas de desenvolvimento impulsionado por carros e, segundo Lindau et. al. (2015), nossas cidades crescem de acordo com um modelo de ocupação territorial distante, disperso e desconectado - caracterizado pelo crescimento desmedido, fragmentado e não planejado da mancha urbana. Por consequência, a expansão urbana e independência de mobilidade conduziram a um aumento no número de viagens feitas por veículos motorizados privados, levando a congestionamentos, resultando em impactos ambientais, sociais, bem como econômicos (Sohonia, Thomasa e Raob, 2016).

Contudo, para Lindau et. al. (2015) o crescimento sustentável pode agir como uma contramedida potencial e um elemento crucial para um futuro sustentável; é a coordenação entre o ordenamento do território e planejamento do sistema de transporte agindo como peça fundamental para reorientar as políticas e estratégias de desenvolvimento urbano de forma a integrá-las ao planejamento da cidade e seus sistemas de transporte. (ITDP, 2017).

Como metodologia, o trabalho parte em busca de repertório bibliográfico para a compreensão do conceito e das estratégias do DOTS; consistindo em uma análise exploratória baseada em pesquisas e levantamentos de mobilidade realizados na UFSC e em Florianópolis, de forma a compreender o objeto de estudo, a atual mobilidade no campus e as projeções de planejamento realizadas por órgãos competentes e suas conexões com a cidade. Ao final, com o cruzamento das informações, pretende-se apresentar o panorama atual do campus e uma breve compilação e proposição de diretrizes conceituais propostas pelos autores do presente estudo, mediante as bases do conhecimento teórico obtido na pesquisa de desenvolvimento urbano orientado ao transporte sustentável. Diretrizes estas que possam servir como base para futuras pesquisas que tenham como objetivo principal a análise e busca alternativas para o planejamento e intervenção urbana voltada para o desenvolvimento sustentável para o Campus Trindade da UFSC.

\section{A UNIVERSIDADE FEDERAL DE SANTA CATARINAEADEFINIÇÃODEDESENVOLVIMENTO ORIENTADO AO TRANSPORTE SUSTENTÁVEL}

A Universidade Federal de Santa Catarina (UFSC) foi fundada em 18 de dezembro de 1960, sucedendo-se como um polo irradiador de desenvolvimento social e urbano, em nível estadual e federal (Ecker, 2016). Localizada na ilha de Santa Catarina com população estimada (2017) de 485.838 pessoas, população no último censo (2010) de 421.240 pessoas e densidade demográfica (2010) de $623,68 \mathrm{hab} / \mathrm{km}^{2}$ (IBGE, 2017). Também se leva em consideração a atratividade que a universidade exerce sobre a região, como a demanda por bens e serviços e os fluxos regionais e intraurbanos, que são por ela desencadeados, correspondendo a 38.219 deslocamentos diários de origem/destino (Bepler et al, 2010).

O Desenvolvimento Orientado ao Transporte Sustentável (DOTS, em tradução do termo original em inglês "Transit Oriented Development") é um conceito relativamente novo de desenvolvimento urbano, e implica em um desenvolvimento compacto, uso misto em torno de uma estação de trânsito para incentivar o público a usar os transportes públicos e reduzir a dependência de veículos privados (Abdullah e Mazlan, 2016 e ITDP, 2017).

Deste modo, o trânsito pode permitir que uma cidade utilize suas forças de mercado para aumentar densidades perto de estações onde se situam a maioria dos serviços, criando assim centros mais eficientes para reduzir a expansão urbana (Sohonia, Thomasa e Raob, 2016). Calthorpe (1990) acrescentou mais detalhes à definição como: um projeto de configuração de mistura de usos para enfatizar um ambiente orientado a pedestres e reforçar o uso de transportes públicos. Já para Hope for 
the Future: The Western Australian State Sustainability Strategy (Western Australia, 2003) expõe-se a necessidade de gerenciar o crescimento urbano e regional, revitalizar centros em declínio e subúrbios e integrar o uso da terra com transportes equilibrados, procurando diminuir a dependência do automóvel. Para Newman e Kenworthy (1999) e para Banister et al. (2006) o desenvolvimento sustentável visa criar um ambiente urbano que maximiza o desenvolvimento econômico e a equidade social, e ao mesmo tempo minimizar as externalidades negativas sobre o ambiente natural.

Na próxima etapa, a pesquisa se direciona para as categorias de análise buscando evidenciar a situação atual da UFSC, bem como as atuais proposições de projetos em andamento, com o objetivo de evidenciar seu conhecimento e propor diretrizes de implantação para os DOTS.

No Manual de Desenvolvimento Urbano Orientado ao Transporte Sustentável (DOTS Cidades, 2015) é sugerida uma concepção integral de desenho urbano para o desenvolvimento de áreas com diferentes usos e funções, sejam novas ocupações ou renovações urbanas, visando à mobilidade sustentável. Está baseado na implementação prática de sete elementos, princípios estes que o presente trabalho adota como categorias de análise para o objeto de estudo. São eles: 1. Transporte coletivo de qualidade; 2 . Mobilidade não motorizada: calçadas e ciclovias; 3. Gestão do uso do automóvel; 4. Uso misto e edifícios eficientes; 5 . Centros de bairro e pisos térreos ativos; 6 . Espaços públicos e recursos naturais; 7 . Participação e identidade comunitária.

\section{ABORDAGEM DO DOTS NA UFSC SOB AS CATEGORIAS DE ANÁLISE}

\subsection{Categoria I: Transporte coletivo de qualidade}

\subsubsection{Panorama na UFSC}

Vários estudos e projetos foram realizados nos últimos anos para enfrentar os problemas de transporte coletivo na região da Grande Florianópolis. Segundo a Prefeitura de Florianópolis o Plano de Mobilidade tem como proposta a criação do Corredor BRT Volta ao Morro, circundando a área central da Ilha de Santa Catarina, a qual é considerada em seus estudos como de melhoria de mobilidade mais sustentável. Sendo assim, foi elaborado projeto conceitual para o Sistema BRT, que engloba a integração do Anel Viário Trecho I (Sul) e Trecho II (Norte), que prevê a implantação de faixas ou corredores exclusivos para o transporte coletivo, integrando os terminais do Centro e Trindade à UFSC.
Comparando-se a Figura 01 - Linhas de ônibus atuais na UFSC com a Figura 02 - Linhas de ônibus pós-instalação do BRT, observa-se que na situação do transporte coletivo atual atende a 25 Linhas e muitas com baixa frequência. Também se constata o desequilíbrio entre bairros adjacentes e o desvio de itinerários das rotas de ônibus. Pretende-se, com a nova implantação dos corredores de BRT, reajustar os itinerários e aumentar a frequência de ônibus, consolidando as linhas de transporte e evitar os desvios de rotas; o projeto prevê também BRT Paradores, Semidiretos e Diretos.

Figura 01 - Linhas de ônibus atuais na UFSC

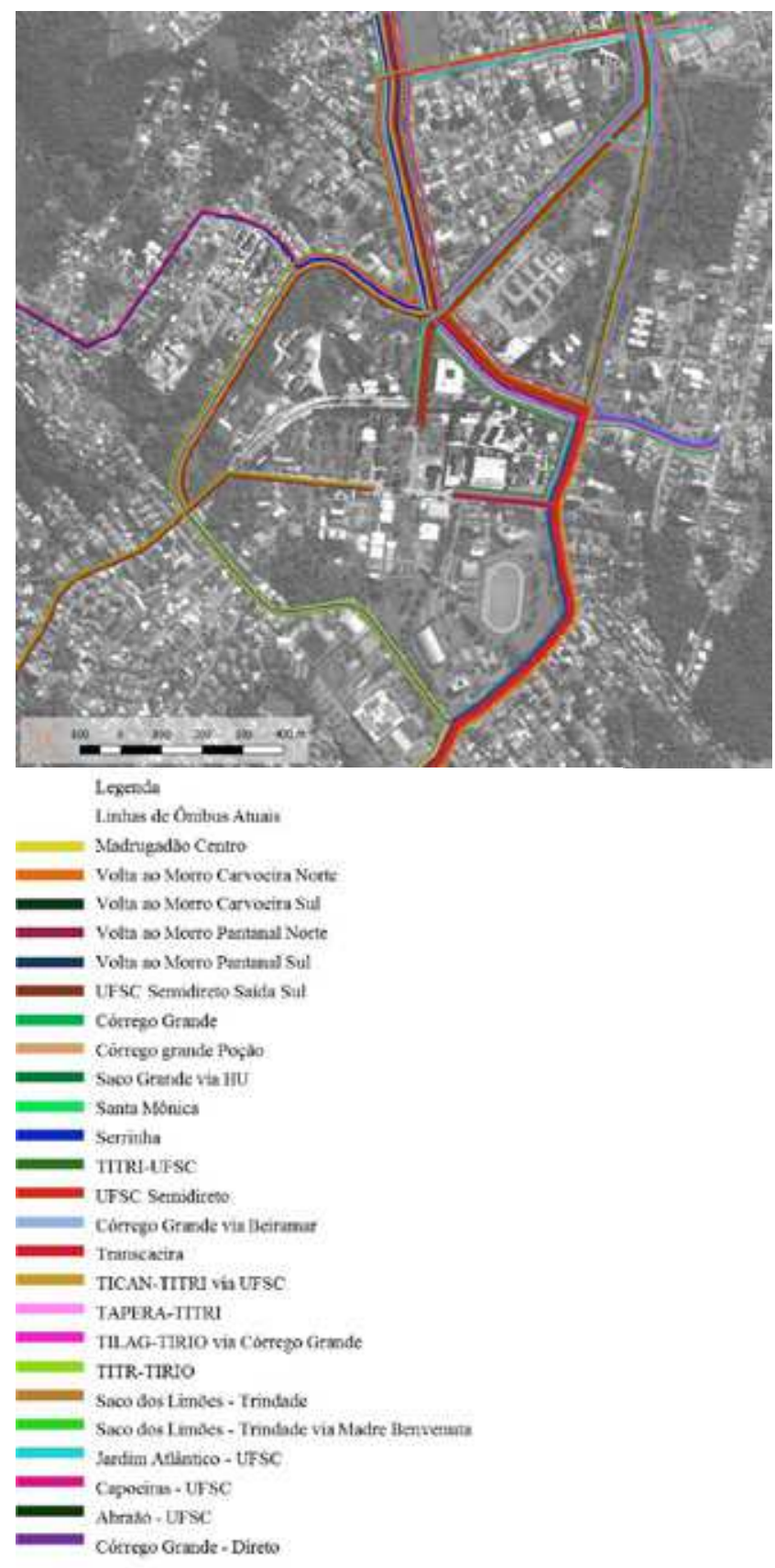


Figura 02 - Linhas de ônibus pós-instalação do BRT na UFSC

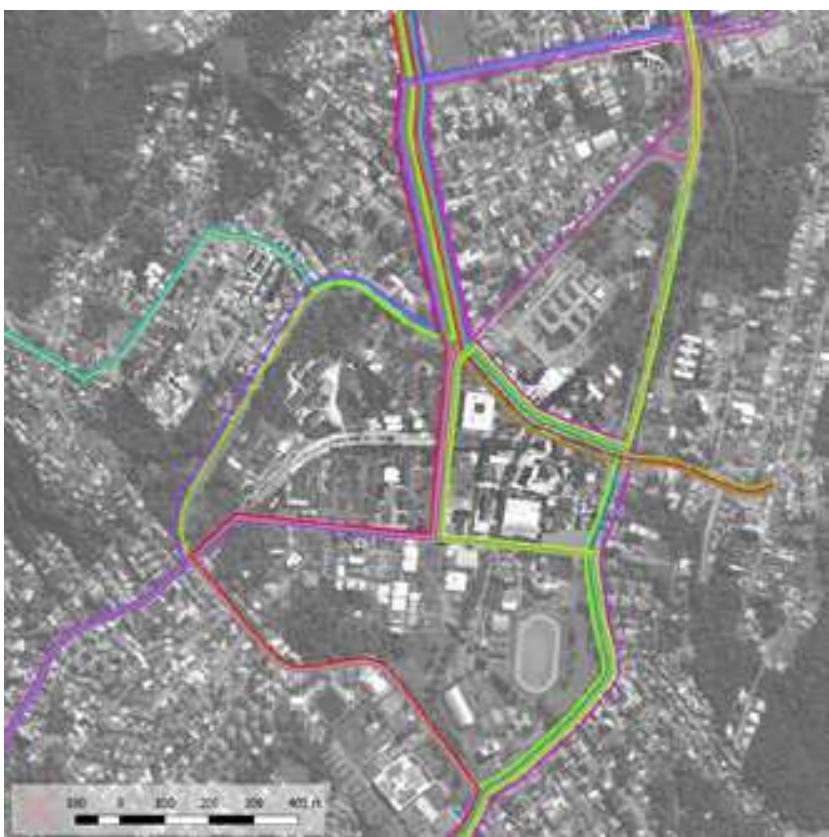

Legenda

Linhas de Ônibus Proposta UFSC

BRT UFSC sentido 1

Volta ao Morro Carvoeira Norte
- Infraestrutura para o transporte coletivo.

\subsection{Categoria II: Mobilidade não motorizada,} calçadas e ciclovias

\subsubsection{Panorama na UFSC}

Na proposta da Prefeitura de Florianópolis para a criação do Corredor BRT Volta ao Morro, também faz parte do sistema a implantação de passeios com acessibilidade global e ciclovias/ciclo faixas ao longo de todos os segmentos urbanizados, sendo este um pedido antigo das comunidades. Pretende-se que essas ações possam melhorar a mobilidade ativa.

Figura 03 - Projeto de ciclovias para UFSC

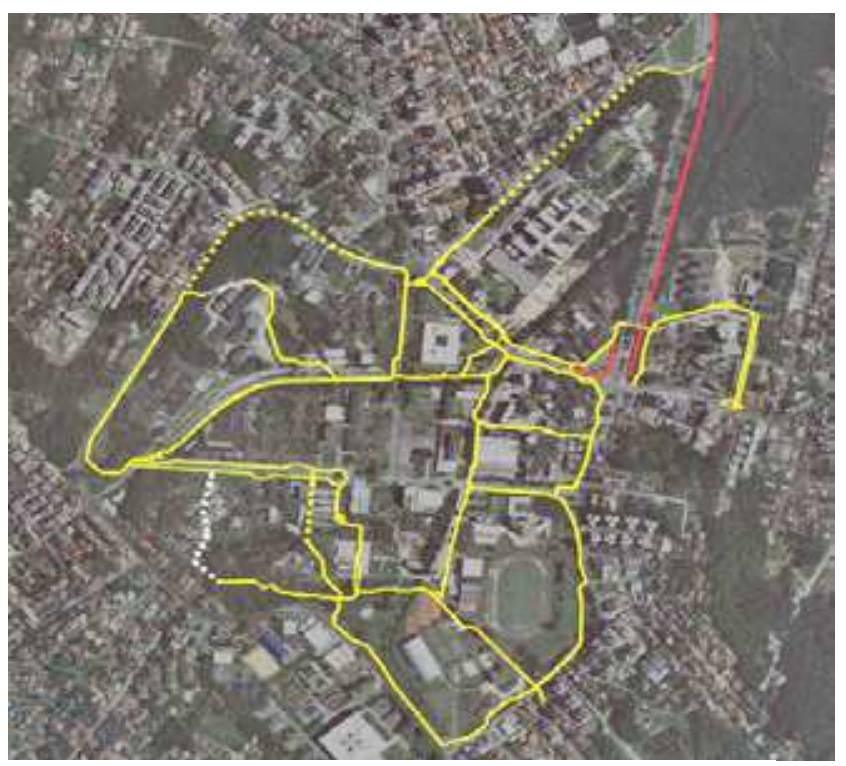

Legenda

Linhas de Ciclovia Proposta UFSC

Ciclofaixa ou ciclovia

I $= \pm$ Passeio compartilhado

I. In 1 Via compartilhada

Ciclovia existente

Fonte: Observatório da mobilidade urbana UFSC, 2017.

Outro estudo com relevante importância é o projeto de ciclovias analisado pelo Observatório da mobilidade urbana UFSC, 2016 (Figura 03).

Estruturou-se a comunicação entre os departamentos da Universidade através de ciclovia ou ciclo faixa, passeio compartilhado ou via compartilhada. Atualmente não existem faixas destinadas ao trânsito de bicicletas no campus, entretanto o uso da bicicleta é bastante difundido, 
apresentando também estacionamento para bicicletas nas dependências de alguns departamentos.

\subsubsection{Diretrizes}

Incrementar viagens de pedestres e ciclistas de modo cômodo e seguro, a incentivar:

- Conectividade interna e a continuidade do traçado viário das ciclovias existentes;

- Redes para pedestres e ciclistas;

- Facilidade de acesso para estacionamento de bicicletas.

\subsection{Categoria III: Gestão do uso do automóvel}

\subsubsection{Panorama na UFSC}

Relativamente à sua integração com o entorno urbano, considera-se a conectividade entre centro-campus, tem-se que, após cruzar a ponte Pedro Ivo Campos (no sentido continente-ilha), a via se bifurca em sentido norte (Av. Gov. Irineu Bornhausen e SC-401) e em sentido sul (Av. Gov. Gustavo Richard), configurando dois trajetos periféricos ao centro urbano. A partir destes trajetos, a Av. Prof. Henrique da Silva Fontes e a Rua Dep. Antônio Edu Vieira conformam um anel viário limítrofe ao campus, configurando vias de fluxo intenso e constante. O caráter expresso deste anel viário, tangenciando o campus, afirma sua característica de axialidade (ECKER, 2016).

A Tabela 01 permite observar que o principal meio de transporte utilizado pela comunidade é o carro (44,01\%), seguido do ônibus (37,7\%). A porcentagem de deslocamento a pé para o Campus da Universidade é de 12,21\%.

Tabela 01: Meios de transporte para chegar à UFSC em porcentagem

\begin{tabular}{|c|c|}
\hline Meio de transporte & $\begin{array}{c}\text { Comunidade } \\
\text { Acadêmica (\%) }\end{array}$ \\
\hline Automóvel como motorista & 44,01 \\
\hline Automóvel como passageiro & 4,82 \\
\hline Ônibus & 37.7 \\
\hline Bicicleta & 0,65 \\
\hline Motocicleta & 0,28 \\
\hline A pé & 12,21 \\
\hline Taxi & 0 \\
\hline Outro & 0,2 \\
\hline
\end{tabular}

Fonte: BEPLER; PRIM, 2010.

Debatin et.al (2012) apontam para a baixa atratividade e o alto custo do transporte público, que contribuem para o uso extensivo do transporte individual. Esta intensa utilização do automóvel gera um valor de viagens altíssimas, 15.918 viagens por dia incentivando aos congestionamentos nos horários compreendidos entre as $6 \mathrm{~h}$ e $24 \mathrm{~h}$.

\subsubsection{Diretrizes}

Gerar ambientes seguros e agradáveis pela racionalização do uso do automóvel.

- Vias seguras e ordenadas que respeitem os modais de transporte ativo;

- Gestão dos estacionamentos;

- Aperfeiçoar percursos;

- Segurança viária em prol do pedestre.

3.4. Categoria IV: Uso misto do solo e edifícios eficientes

\subsubsection{Panorama na UFSC}

Ecker (2016) analisa o uso do solo nas proximidades da UFSC, para o qual o perímetro viário ao entorno da UFSC entre um lado e o outro da via, se apresenta como uma barreira físico-espacial para o fluxo de pedestres. Tornando-se mais crítico no trecho em frente ao campus, onde se concentra os estabelecimentos comerciais (restaurantes, bares, copiadoras, farmácias, etc.).

A Figura 04 apresenta cada rua principal do entorno e evidencia a estruturação do uso do solo. O Perímetro viário da UFSC apresenta uma ampla variedade de usos, como: casas, habitações multifamiliares, bares, morada estudantil, clube recreativo da Elase e edifícios institucionais (Eletrosul). $\mathrm{Na}$ Av. Madre Benvenuta estão presentes os equipamentos de maior porte, tais como Shopping Center, igreja, escolas, edifícios em altura e corporativos. Na Av. Lauro Linhares concentram-se as atividades e serviços que atendem, ao público universitário residente no bairro da Trindade. A Av. Cap. Romualdo de Barros os serviços estão voltados ao público universitário (que residem nos bairros da Carvoeira e Serrinha) como: restaurantes, bares, padarias, minimercados. A Rua Eng. Agronômico Andrei Cristian Ferreira concentra os acessos secundários de leste a oeste e intercepta o campus de fora a fora, com faixas de rolamento dupla e estacionamentos em sentido paralelo. Na Rua Deputado Antônio Edu Vieira é grande a presença de edifícios de habitação multifamiliar, posto de saúde e empresas privadas. Já na Rua João Pio Duarte Silva faz-se presente edifícios de uso misto com lojas comerciais térreas; esta rua também se conecta ao Parque Municipal do Córrego Grande.

No interior das quadras da UFSC encontram-se os prédios administrativos e institucionais de cada departamento. 
Entre os prédios intercomunicam-se caminhos secundários de pedestres e vias de porte menor para estacionamentos.

Figura 04 - Uso do solo conforme o caráter viário do entorno

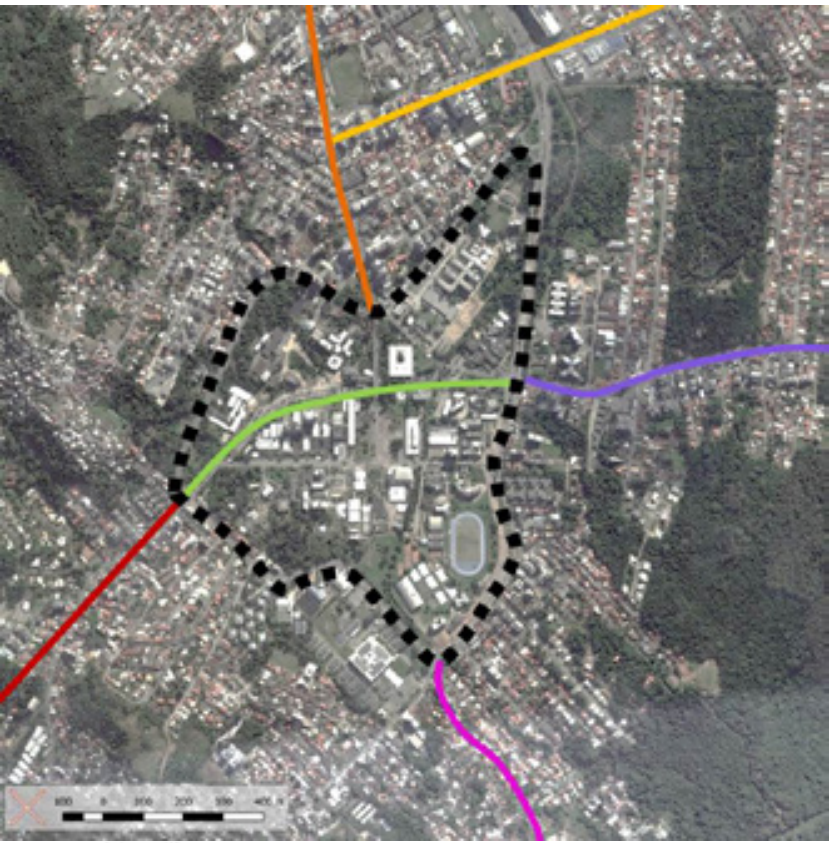

Legenda

Uso misto do solo

1 - . Perimetro viário

- Diversidade de usos: casas, habitaçócs multifamiliares, bares, morada estudanti. chube recreativo e edificios instifucionais

v. Madre Benvenut:

- Equipamentos de maiot porie, tais como Shopping Center. igreja, eseolas

Av. Lauro Linhares

- Atividades e serviços que atendem, to público universiririo residente no bairro da Trindade

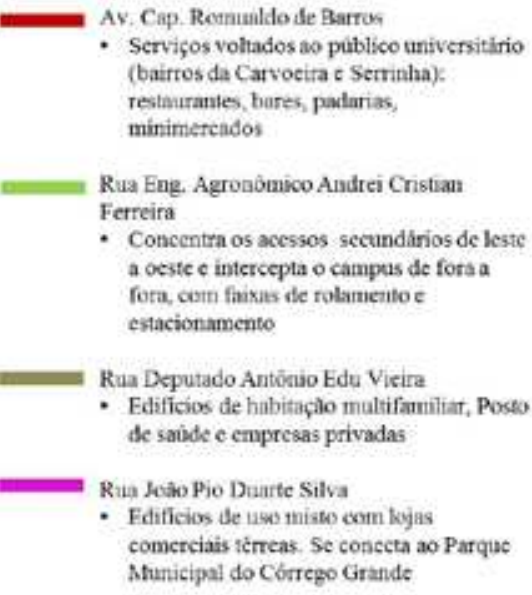

Rua Deputado Antồcio Edu Vieira

- Edifícios de hubitaçao multifamiliar, Poseo de saùde e empresas privadas

Ria Jeta Pio Darite Silya

- Fdificios de luse misces com kejas

comerciás térreas. Se conecta ao Parque

Afuricipal do Córrego Grande

Fonte: Elaborado pelo autor(2018).

\subsubsection{Diretrizes}

Devido a alta consolidação do entorno, recomenda-se potencializar atividades e os caminhos para pedestre para melhor intercomunicar o campus com as atividades e serviços existentes, de modo a promover uso do solo pelos estudantes, professores e funcionários e diversificar a interação com o entorno. Implementar também:

- Equipamentos de bairro e comércio;

- Mobiliários de estar e permanência;

- Edifícios mistos com lojas térreas;

- Fomentar a integração pedestre-rua.

\subsection{Categoria V: Centros de bairro e pisos térreos ativos}

\subsubsection{Panorama na UFSC}

Desde a fundação da UFSC, os bairros do entorno transformaram-se de zona rural à urbana, caracterizando uma ocupação quase extensiva do solo urbano. Estas transformações alteraram a paisagem, o traçado urbano, o comércio, as condições imobiliárias, a vida social e os costumes da região. Atualmente continuam centralizando investimentos, não só diretamente relacionados às atividades da UFSC e demais instituições públicas, mas também relacionadas ao setor habitacional. Cada bairro apresenta uma conexão com o perímetro viário da Universidade, tornando-a assim um importante agente de centralidade urbana A seguir, a Figura 05 apresenta a localização de cada bairro nas proximidades da Universidade e a Figura 06 menciona os principais serviços e atividades, que influem nas dinâmicas territoriais e no cotidiano do público que frequenta a universidade.

Figura 05 - Localização dos bairros do entorno

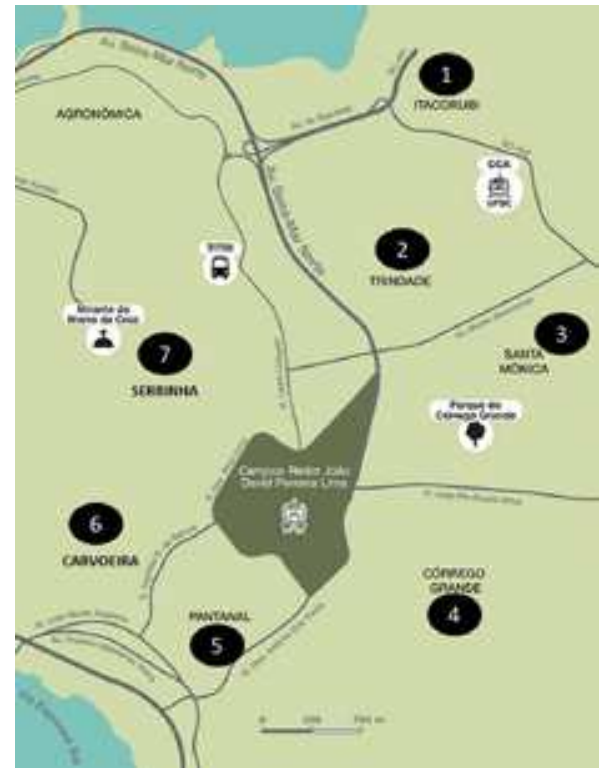

Fonte: Adaptado de UFSC (2018). 
Figura 06 - Descrição territorial do bairro

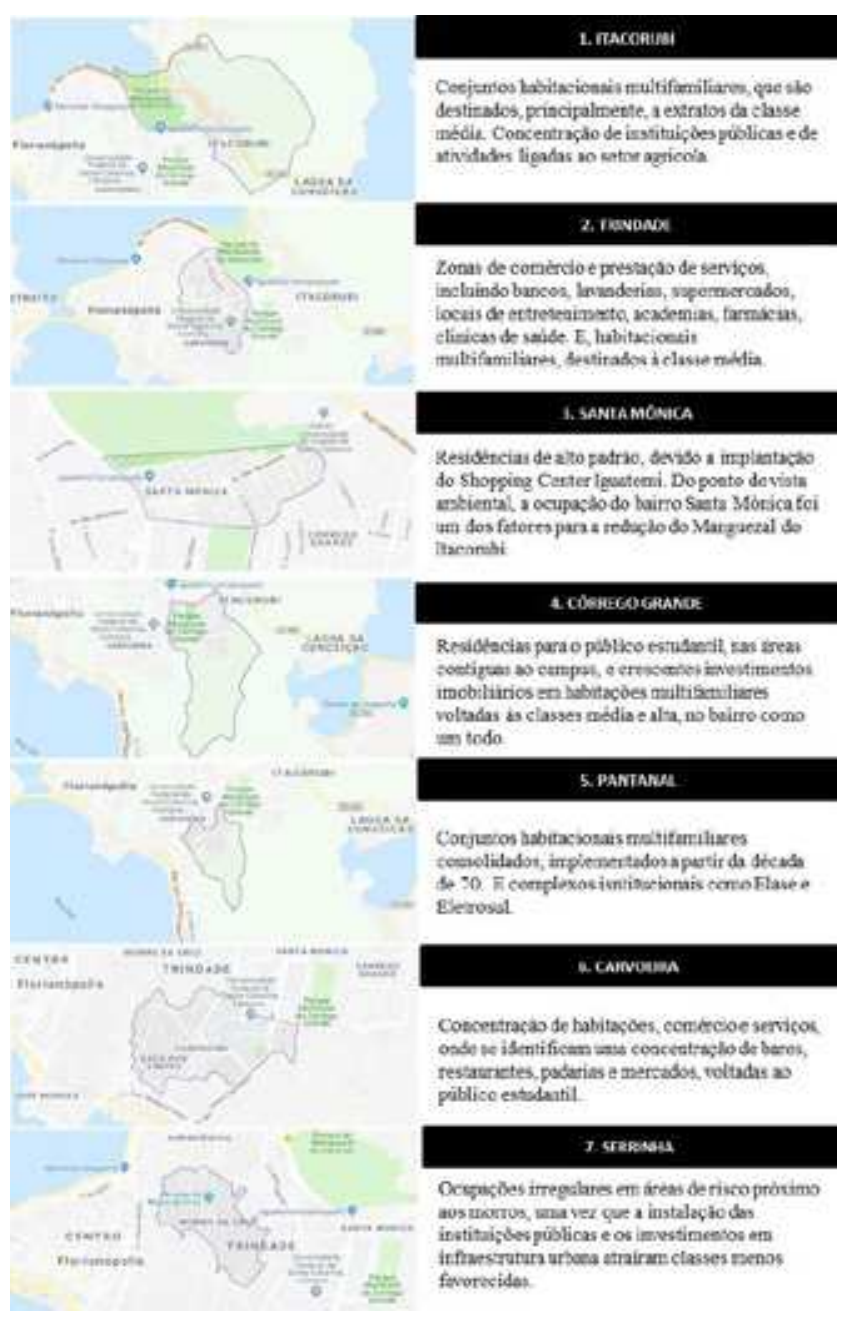

Fonte: Adaptado de ECKER (2016)/ GOOGLE MAPS (2018).

\subsubsection{Diretrizes}

Promover interação social com usos que aproximem espaço público e ambiente construído através de transformações que iniciem na Universidade como porta de acesso para cada bairro do entorno, fortalecendo relações urbanas com exponencial atratividade para:

- Centros de bairro ativos e interligados;

- Pisos térreos ativos;

- Incentivo para economia local;

- Transição público-privado.

\subsection{Categoria VI: Espaços públicos e recur- sos naturais}

\subsubsection{Panorama na UFSC}

O Campus da UFSC, com área aproximada de $4 \mathrm{~km}^{2}$, foi implantado ao leste da Ilha de Santa Catarina, na Bacia Hidrográfica do Rio Itacorubi, uma zona de transição entre as encostas, o manguezal e o mar. A Bacia do Itacorubi possui uma área de aproximadamente $23 \mathrm{~km}^{2}$, e abrange os bairros Trindade, Pantanal, Itacorubi, Córrego Grande e Santa Mônica (SANTOS, 2003).

Com relação a estas bacias hidrográficas: "a Bacia do Itacorubi é drenada por rios e seus afluentes, além de possuir alguns canais de drenagem menores. O Rio da Carvoeira e o Rio do Sertão interceptam a área do Campus da UFSC" (ECKER 2016, pg.115). "As principais APP's existentes no entorno da UFSC são: o Parque Municipal do Manguezal do Itacorubi, o Parque Ecológico do Córrego Grande, o Parque Municipal do Maciço da Costeira e Parque Urbano do Morro da Cruz" (ECKER 2016, pg.117).

Desde a fundação do campus até atualmente, identifica-se um uso intensivo do solo urbano, justificado pela crescente demanda por novas edificações. Estas intervenções resultaram, entretanto, em edificações construídas sem um planejamento global, o que Ecker (2016) caracteriza como uma contribuição para o desperdício do espaço físico existente.

\subsubsection{Diretrizes}

Estabelecer como prevê o Plano Diretor de 2005, a necessidade de proposição de um sistema de áreas verdes, de uso público, no campus para gerar espaços públicos seguros e ativos e fomentar a preservação das áreas de preservação ambiental, propondo:

- Áreas verdes estratégicas e intercomunicantes entre si;

- Eficiência em energia, água e resíduos;

- Áreas específicas para a rede de espaços públicos e vida pública;

- Preservar áreas puramente ambientais e regenerar as danificadas ambientalmente.

\subsection{Categoria VII: Participação e identidade comunitária}

\subsubsection{Panorama na UFSC}

Como instituição federal de ensino superior, a UFSC, tem o compromisso com a sociedade em cursos de educação básica, graduação e pós-graduação. A Tabela 02 evidencia o número da população que frequenta a Universidade para o ano de 2016.

Implementou-se na Universidade as condições para dar conta das demandas de uma universidade que confirma o seu status entre as melhores do País e da América Latina: trabalhando no ensino, na extensão, na pesquisa, na cultura, no planejamento, na comunicação e na gestão de pessoal, a UFSC direciona-se para a pluralidade, 
democratização na educação e na saúde, promovendo e patrocinando as transformações exigidas pela população que sustenta a Instituição.

Tabela 02: População em números

\begin{tabular}{|c|c|}
\hline Matriculados & Total: 45.000 \\
\hline Educação Básica & 1.178 \\
\hline Graduação & 20.395 \\
\hline Pós-Graduação & 14.276 \\
\hline Diplomados & Total: 4.411 \\
\hline Educação básica & 150 \\
\hline Graduação & 3.375 \\
\hline Pós-Graduação & 5.406 \\
\hline \multicolumn{2}{|c|}{ Docentes } \\
\hline \multicolumn{2}{|c|}{2.670} \\
\hline \multicolumn{2}{|c|}{ Técnico-administrativo } \\
\hline & \\
\hline
\end{tabular}

Fonte: Fonte: UFSC, 2018.

Destacam-se cursos inovadores, programas pedagógicos, aumento de $50 \%$ nas vagas no Vestibular, humanização do campus, alimentos orgânicos no Restaurante Universitário, disponibilização de museu para a população, fortalecimento público do Hospital Universitário e revitalização das bibliotecas.

Além de fornecer a estrutura para a formação do conhecimento, a UFSC também promove a inovação, a inclusão social com ações e projetos nas áreas da Saúde, Assistência Social, Lazer, Arte e Cultura, com serviços gratuitos mencionados e listados na Tabela 03:
Tabela 03: Serviço, apoio e parcerias oferecidos na Universidade

\section{Serviços}

Fonoaudiologia/Voze Audição/Odontologia/Psicologia/ Apoio a Imigrantes e Refugiados/ Clínica Intercultural/ Assistência Jurídica/ Farmácia/ Terapias/ Aleitamento Materno/ Terceira Idade/ Leishmaniose e Doença de Chagas/ Prática de Neurofeedback para o Estresse

\section{Apoio e estrutura}

\section{Biblioteca Central}

(Sistema de Bibliotecas Universitárias e Ambiente de Acessibilidade Informacional/ Acervo digital/ Círculo de Leitura de Florianópolis/ Espaço de Inclusão Digital/ Núcleo de Estudos da Terceira Idade (Neti)

\section{Hospital Universitário (HU)}

Grupo de gestantes e casais grávidos/ Atendimento multiprofissional para prevenção e tratamento de dislipidemias na comunidade universitária/ Ações de nutrição a pacientes com doença renal crônica no SUS/ Grupo Interdisciplinar de Acompanhamento a Pacientes com Redução de Estômago/ Projeto HPV - vacina preventiva contra os quatro principais vírus causadores do papilomavírus humano/ Maternidade/ Método Mãe Canguru - humanização do atendimento ao recém-nascido prematuro/ Sala de Leitura Salim Miguel/ Casa de Acolhida Amigos do HU

\section{Parcerias}

Centro de Informações Toxicológicas (CIT)/ Sistema Catarinense de Telessaúde e Telemedicina/ Praça da Cidadania

Fonte: UFSC, 2018.

\subsubsection{Diretrizes}

Incentivar participação comunitária para identidade e integração do bairros na Universidade, fazendo com que a população homologue decisões urbanísticas mediante o contato a aprovação da comunidade local., que promovam:

- A identidade local;

- A promoção de ambientes seguros e equitativos;

- Vincular os cidadãos locais;

- Administração comunitária em contato com os bairros. 
3.8. Desenvolvimento do veículo automotivo $x$ desenvolvimento oreintado ao transporte sustentável

Na situação atual do campus o principal modal de transporte utilizado é o veículo automotivo. $O$ automóvel possibilitou o desenvolvimento de zonas afastadas da região central, exercendo um contato do centro com o exterior criando polos de variados tipos, que servem de suporte urbano a atividades polarizadoras. Impeliu um processo de desarticulação nas cidades, atraindo diferentes pontos de oferta de serviços, e consequentemente, levando à formação de um tipo de cidade baseada no automóvel.

Com esta expoente disseminação do automóvel: vieram os congestionamentos, os altos níveis de poluição atmosférica, o espaço requerido para circular e estacionar o veículo automotivo foi ficando cada vez mais indisponível acarretando na descaracterização do passeio de pedestres e competição de fluxos entre ciclistas, pedestres e motoristas. Estas são circunstâncias desastrosas facilmente constatadas nos arredores das vias principais da UFSC atualmente.

Ao analisar as informações de mobilidade mediante os princípios de equidade e de qualidade de vida, verificou-se nas diversas bibliografias que a aplicação do DOTS nas centralidades urbanas permite torná-los como serviços de trânsito mais elevados, para onde eles estão disponíveis para uma gama maior de variedades urbanísticas que não apenas para atender o maior número de viagens e posteriormente maior potencial para geração de número de passageiros do trânsito.

Esta extensão da mobilidade sustentável pode dar origem a oportunidades para o desenvolvimento da região como um todo, incluindo fatores como o incentivo a um transporte coletivo de qualidade, mobilidade não motorizada com calçadas e ciclovias qualificadas, garantindo uma melhor gestão do uso do automóvel, atribuindo edifícios mais eficientes com uma variedade maior de uso misto do solo com centros de bairro e pisos térreos ativos, valorizando espaços públicos e recursos naturais e incentivando a participação comunitária como parte dos esforços de revitalização.

Mediante o planejamento da Prefeitura de Florianópolis percebemos a relevância deste assunto sendo abordado pela municipalidade, fato que revela sua extrema importância para a equidade, desenvolvimento e o bem estar da população menos favorecida. Levar em conta todos os princípios do DOTS permitirá uma gestão mais eficiente do uso do automóvel que intensifique o contato do usuário com os caminhos e atividades dos edifícios e do espaço público, gerando uma maior vitalidade e segurança.

\subsection{CONSIDERAÇÕES FINAIS}

A partir do panorama da UFSC e com a apresentação dos cenários das categorias de análise, conclui-se que atualmente o campus da UFSC não atende aos requisitos do DOTS por apresentar uma série de problemas como a alta utilização do veículo automotivo, ineficiência do transporte público, e a falta de oferta de espaços adequados para o transporte ativo bem como a desvalorização do espaço público de lazer e de preservação ambiental.

As diretrizes apresentadas pela pesquisa podem servir para orientar a elaboração de ferramentas e estratégias que visem a efetivação de um programa de necessidades para a implementação de um Desenvolvimento Orientado ao Transporte Sustentável na UFSC. Entretanto os projetos propostos pela Prefeitura Municipal de Florianópolis de remodelação viária, implantação do BRT e de ciclovias já elaborados (que ainda não se encontram em implantação / execução) poderão orientar o campus para Desenvolvimento Orientado ao Transporte Sustentável. A efetivação da implantação de uma infraestrutura de viagens de transporte coletivo mediante as novas conexões e frequência do BRT permitirá a viabilidade de transporte público para uma demanda maior de população para a UFSC e seu entorno; a criação de ciclovias e a requalificação de calçadas proporcionarão também o incentivo às viagens de ciclistas e pedestres; o que auxiliará a diminuir o alto congestionamento das vias e lotação de estacionamentos no campus.

Contudo, este desenvolvimento sustentável não parte apenas de uma infraestrutura viária para suprir a demanda da população por transporte. A Política Nacional de Mobilidade Urbana, expressa pela Lei 12.587 de 3 de janeiro de 2012, apresenta o entendimento de que o problema de mobilidade vai além da simples provisão de infraestrutura para atendimento da demanda, indicando que a mobilidade é instrumento de desenvolvimento urbano e que deve ser estudada tendo em vista a relação entre os deslocamentos e o meio urbano em que ocorrem. Nesse sentido, torna-se fundamental a análise da mobilidade à luz dos padrões de uso do solo urbano e de ocupação do território.

As diretrizes do planejamento que o estudo sugere para o campus da UFSC é fornecer incentivo para que viagens com distância inferior a 1 quilômetro possam ser realizadas por caminhada e que viagens curtas possam ser realizadas de bicicleta. Para isso, é necessário prover infraestrutura atraente e segura para caminhar e circular com bicicleta. As redes de calçadas apropriadas para pedestres e deficientes, e de espaços dedicados à circulação e estacionamento de bicicletas devem irradiar-se a partir de áreas de grande atração de viagens e de polos geradores. 
As medidas de requalificação das áreas naturais visam permitir que o ecossistema proporcione um bem estar e equilíbrio bioclimático e de microclima para a população local reforçando a necessidade de conscientização e de preservação ambiental com estas áreas. Todas estas estratégias se vinculam e devem incentivar um convite à participação comunitária para reforçar a identidade e a integração de bairro, e promover ambientes seguros, os quais não sejam apenas caminhos de transição, mas espaços repletos de permanência e convívio social equitativo repleto de ruas vivas e atraentes, quadras e fluxos que facilitem o deslocamento do pedestre, com um tecido urbano o mais contínuo possível, repleto de identidade funcional das áreas que priorize parques, praças, espaços públicos e edifícios públicos como instrumentos capazes para compor e intensificar a complexidade e multiplicidade de usos e atividades, evitando o isolamento de áreas.

\section{REFERÊNCIAS}

ABDULLAH, J.; MAZLAN, M. Characteristics of and Quality of Life in a Transit Oriented Development (TOD) of Bandar Sri Permaisuri, Kuala Lumpur. In: ASEAN-Turkey ASLI (Annual Serial Landmark International), AMER International Conference on Quality of Life. Medan, Indonesia, Procedia -

BANISTER, D.; PUCHER, J.; LEE-GOSSELIN, M. Institutions and Sustainable Transport: Regulatory Reform in Advanced Economies. (Ed, Rietveld, P.) London, Edward Elgar, 2006.

BRASIL. Lei no 12.587, de 03 de janeiro de 2012. Diário Oficial da União, Brasília/DF, p. 1, 04 de jan. de 2012.

BEPLER, F.;PRIM,D. Análise do Campus da Universidade Federal de Santa Catarina como um pólo gerador de viagens. Relatório de Pesquisa PET/ECV/UFSC, 2010.

DEBATIN, A.; MIRANDA, F.; GIARETTA, F. A UFSC no contexto da mobilidade em Florianópolis. In: $5^{\circ}$ Congresso Luso - Brasileiro para o Planejamento Urbano Regional Integrado e Sustentabilidade (PLURIS). Brasília, 2012.

ECKER, V. A praça como locus da sociabilidade estudo de caso da Praça da Cidadania, no campus da UFSC. Dissertação (mestrado) - Universidade Federal de Santa Catarina, Centro Tecnológico, Programa de PósGraduação em Arquitetura, Urbanismo e História da Cidade, Florianópolis, 2016.

INSTITUTO BRASILEIRO DE GEOGRAFIA E ESTATISTICA (IBGE). Panorama: População. Disponível em: <https://cidades.ibge.gov.br/brasil/sc/florianopolis/panorama> Acesso: 20 nov. 2017.

LINDAU, L; et. al. Manual de desenvolvimento urbano orientado ao transporte sustentável. DOTS CIDADES - EMBARQ Brasil, 2ed. mai. 2015.

NEWMAN, P; KENWORTHY, J. R. Sustainability and cities: overcoming automobile dependence. Washington, D.C., Island Press, 1999.

OBSERVATÓRIO DA MOBILIDADE URBANA UFSC. Projetos ciclovias UFSC. In: Seminário e Debate "Mobilidade Urbana na UFSC e seu Entorno". Universidade Federal de Santa Catarina, set. 2016. Disponível em: <http://observatoriodamobilidadeurbana.ufsc.br/files/2016/05/2.-Ciclovias-na-FSC.pdf> Acesso: 30 out. 2017.

PREFEITURA DE FLORIANÓPOLIS. Projetos de mobilidade urbana - Floripa BRT. Secretaria de Obras: Anel viário para Corredor de Transporte Coletivo. Versão Preliminar, Prosul. República Federativa do Brasil. Governo do estado de Santa Catarina. Prefeitura Municipal de Florianópolis. Disponível em: <http://www.pmf.sc.gov.br/ entidades/infraestrutura/index.php?cms=obras+de+mobilidade+em+florianopolis> Acesso: 04 nov. 2017.

SANTOS, C. O processo de urbanização da Bacia do Itacorubi: a influência da UFSC. Dissertação (Mestrado). Programa de PósGraduação em Engenharia Civil. Universidade Federal de Santa Catarina, Florianópolis, 2003.

SOHONIA, A.; THOMASA, M.; RAOB, K. Application of the concept of transit oriented development to a suburban neighborhood. In: World Conference on Transport Research - WCTR 2016 Shanghai, Transportation Research Procedia 25, p. 3220-3232, jul. 2016.

UFSC. Departamento de Planejamento e Gestão da Informação. Disponível em: < http://dpgi.seplan. ufsc.br/> Acesso: 15 abr. 2018.

WESTERN AUSTRALIA. Sustainability Policy Unit Hope for the future - the Western Australian state sustainability strategy. In Western Australia. Department of the Premier and Cabinet and Western Australia, Perth, W.A., 2003. 